\title{
Parenting Style and Shyness of Late Adolescence Students in China: The Mediating Effect of Parent-Child Attachment ${ }^{*}$
}

\author{
Chen YingMin, Liu XiaoRan, Yu LiNa, Wu YunPeng, Han Xue \\ Shandong Normal University, Ji'nan, China
}

\begin{abstract}
Objective: The current study intended to investigate the relationships between the shyness level of late adolescence students, parenting style and parent-child attachment. Methods: Totally 705 senior high school students reported their shyness level, the parenting style of their parents, and their attachment with parents. Results: (1) Parents' excessive protection and interference of parenting style and alienation dimension of parent-child attachment have a significant positive prediction on the shyness level of high school students; paternal emotional warmth has a significant negative prediction on students' shyness level; and (2) The parent-child attachment showed partial mediating effect on the relationship between the parenting style and shyness level of late adolescence students. Conclusion: Parenting style not only can directly affect late adolescence students' shyness, but also indirectly affect their shyness through parent-child attachment.
\end{abstract}

Keywords: shyness, parenting style, parent-child attachment, late adolescence, mediating effect

\section{Introduction}

Shyness refers to the discomfort and behavioral inhibition in social situations, a fear of negative evaluation accompanied by emotional distress or inhibition that interferes significantly with participation in desired activities and with the pursuit of personal and professional goals (Henderson \& Zimbardo, 1998). It's obvious that higher shyness may have more negative influence on the individuals' psychology and behaviors. For high school students who are in the late adolescence stage, their physical and psychology are changing rapidly. The gradual maturity of sexual physiology, the germination of sex psychology, and the rapid development of self-consciousness make them more likely to show shyness when they are in the situation of facing opposite sex, or circumstances that concerning self-evaluation especially negative evaluation. Modest shyness would not cause serious consequences, but if the level of shyness is too high, it may bring about obstacles and troubles to individuals' adaptation and development, such as academic, emotion, dating, marriage, career and so forth, even lead to social anxiety and other mental disorders, which will damage seriously individuals' health and development (Jakobsen, Horwood, \& Fergusson, 2012). Therefore, exploring the possible influence factors will have positive

\footnotetext{
* Acknowledgments: This research was funded by project of National Social Science Foundation of China (13BSH061), Science and Technology Development Plan Projects of Shandong Province (2013GSF11802). The Key Discipline Construction Program of 12th Five-year Plan of Shandong province (Developmental and Educational Psychology). And by two projects of Humanities and Social Sciences of the Ministry of Education of China (12YJC190004, 12YJC190009).

Chen YingMin, Ph.D., School of Psychology, Shandong Normal University.

Liu XiaoRan, M.A., School of Psychology, Shandong Normal University.

Yu LiNa, M.A., School of Psychology, Shandong Normal University.

Wu YunPeng, Ph.D., School of Psychology, Shandong Normal University.

Han Xue, M.S., School of Psychology, Shandong Normal University.
} 
significance on the prevention of high school students' shyness and dealing with problems caused by shyness.

Previous studies found that there are many factors of causing shyness, including genetic and neurophysiological mechanism, environment, and individual psychological factors (Chen, 2013). Among all kinds of environmental factors, family surrounding is the first environment of individual growth and development; in particular, parents' rearing style can influence the children's psychology and behavioral performance (Xu, 2014). Different researchers have different definitions about parenting style. Frances believes that parenting style refers to a stable complex of attitudes and beliefs about parenting (Frances, 2003). Researchers have found that children's shyness is closely associated with parenting style, some parenting practices more easily lead to children's escape behavior, shyness and anxiety, for examples, parents do not accept, reject and control; neglect, indifference, low emotional warmth and understanding, over-protection. Meanwhile many researchers concluded that parenting practices of accept, care, emotional warmth, democracy and tolerance, understanding and respect, which can reduce children's shyness (Han, Gao, \& Ping, 2012; Chen, Liu, \& Li, 2000).

Attachment is a stable and continuous affection bonding between individuals and the important others, especially their parents (Wu \& Wang, 2014). Attachment theorists divided the attachment into two types: secure attachment and insecure attachment. Secure attachment individuals are easier to accept and trust others, no matter with relatives or strangers, but insecure attachment individuals is just the opposite; they tend to have more criticisms or doubts to their relatives or strangers. The positive performance of the former make them show more confidence in interpersonal situations, more flexibility and adaptability, so it is not easy for them to generate shyness; on contrast, the latter are easier to produce shyness, because it is difficult for them to communicate friendly and freely, thus they avoid contacting with others and social occasions (Stephen, Jacqueline, Matthew, Sajid, \& Thomas, 2011). High school students are just in the transition period, a stage connects children with adults, and the attachment of this stage will have an important impact on their development.

A large number of studies show that the attachment of adolescents is closely related to the parenting style. In the researches of above relationship, Liuqin has found that parental understanding and care have significant impact on the formation of children's secure attachment, but over meticulous discipline of mother is not conducive to the formation of secure attachment. In addition, parental care and encourage can help adolescents form positive attachment model, and become more trustful of others (Liu, Zhou, Yang, Chu, \& Liu, 2009; Brown, Mangelsdorf, \& Neff, 2012).

Late adolescence students are experiencing the stage of getting independency. We intended to explore whether parenting styles and the attachment between parents and adolescent in this period still have sustained and stable effect on students' shyness? In addition, existing studies have indicated that parenting style and parent-child attachment respectively correlated with shyness. on this basis, we want to make a further investigation that whether parent-child attachment of high school students play a mediating role between parenting style and shyness, so as to make a complement for their correlation relationship.

\section{Method}

\section{Participants}

The participants were selected from two senior high schools from Linzi City, Shandong Province, China by random cluster sampling. We choose four classes in each grade (Grade 10-Grade 12) randomly. The original sample was 705 students. After removing invalid questionnaires, the remaining valid subjects were 689, consisted of 323 boys and 366 girls. 


\section{Measures}

Parenting style. Parenting style were measured by the EMBU (Egna Minnen of Barn Uppfostran), the Chinese version was revised by Yue Dongmei (Yue et al., 1993). This scale is divided into two subscales: mother and father. There are six dimensions in father subscale: paternal emotional warmth, paternal over-protection, paternal favoring, paternal excessive interference, paternal severe punishment, paternal rejection and deny. And five dimensions in mother subscale: maternal emotional warmth, maternal favoring, maternal excessive interference and over-protection, maternal severe punishment, maternal rejection and deny. The Chinese version had 66 items and used 4-point scale ( $1=$ "Never"; 4 = "Always"). In current study, Cronbach's alphas for this scale were 0.943.

Parent-child attachment. Parent-child attachment was measured by IPPA (Inventory of Parent and Peer Attachment; Ju, Liu, \& Fang, 2011). This scale includes three subscales: father, mother, and peer. Each subscale has 25 items and used 5-point scale (ranging from "Almost always or always true" to "Almost never or never true"), and including three dimensions: trust, communication and alienation. According to the objective of this study, we only adopt the mother attachment subscale and father attachment subscale, the higher score means higher levels of attachment. In current study, Cronbach's alphas for these three factors ranged from 0.626 to 0.806 , with 0.883 for the whole scale.

Shyness of high school students. The shyness of senior high students was assessed by 31-item self-reported shyness scale for junior high school students (Chen, Zhang, Wu, \& Gao, 2015). This scale includes five subscales. Shyness for self-presentation (7 items); Shyness towards stranger (6 items); Shyness when facing negative evaluation (6 items); Shyness towards opposite sex (7 items); Unassuming shyness (5 items). The shyness scale used 5-point scale, the higher scores mean higher degree of shyness. In order to test whether this scale is suitable for senior high school students, we firstly carried out the prediction and examine before the formal application. A total of 395 students were selected from the same Grade 10-12. The result verifies that the shyness scale has good reliability for the measurement of the senior high school students' shyness. In the formal measurement, we found that the reliability and validity of the scale was good. Cronbach's alphas for these five subscales ranged from 0.702 to 0.838 , with 0.941 for the whole scale.

\section{Data Analysis}

Data analysis of statistics was conducted by SPSS 17.0, using correlation analysis and regression analysis.

\section{Result}

\section{Correlations Between Parenting Style, Parent-Child Attachment, and High School Students' Shyness}

The correlation matrix was presented in Table 1 and Table 2. As resulted indicated that the high school students' shyness was negatively and significantly related with the paternal emotional warmth, and positively and significantly related with paternal excessive interference, over-protection, rejection and deny dimensions of paternal style. The high school students' shyness was positively and significantly related with maternal excessive interference and protection, maternal rejection and deny dimensions of maternal style. All dimensions of shyness, except unassuming shyness, were positively and significantly related with paternal alienation; parental trust was negatively and significantly correlated with shyness for self-presentation, shyness towards stranger, shyness towards opposite sex, and positively and significantly related with unassuming shyness. Paternal communication was positively and significantly related with unassuming shyness and shyness when facing negative evaluation. 
Table 1

Correlation Matrix for Paternal Style, Father-Child Attachment, and Shyness

\begin{tabular}{|c|c|c|c|c|c|c|c|c|c|c|c|c|c|c|c|}
\hline & 1 & 2 & 3 & 4 & 5 & 6 & 7 & 8 & 9 & 10 & 11 & 12 & 13 & 14 & 15 \\
\hline 1.Shy-ness & 1 & & & & & & & & & & & & & & \\
\hline 2.sSP & $0.886^{* * *}$ & 1 & & & & & & & & & & & & & \\
\hline 3.sSt & $0.877^{* * *}$ & $0.750^{* * *}$ & 1 & & & & & & & & & & & & \\
\hline 4.sNE & $0.766^{* * *}$ & $0.571^{* * *}$ & $0.521^{* * * *}$ & 1 & & & & & & & & & & & \\
\hline $5 . \mathrm{sOS}$ & $0.848^{* * *}$ & $0.717^{* * *}$ & $0.784^{* * *}$ & $0.489^{* * *}$ & 1 & & & & & & & & & & \\
\hline 6.Uns & $0.600^{* * *}$ & $0.444^{* * *}$ & $0.392^{* * *}$ & $0.491^{* * *}$ & $0.259^{* * *}$ & 1 & & & & & & & & & \\
\hline 7.PEW & $-0.097^{*}$ & $-0.195^{* * *}$ & $-0.125^{* * *}$ & -0.005 & $-0.148^{* * *}$ & $0.164^{* * *}$ & 1 & & & & & & & & \\
\hline 8.PSP & 0.021 & $0.119^{* *}$ & 0.053 & -0.031 & 0.057 & $-0.202^{* * *}$ & $-0.400^{* * *}$ & 1 & & & & & & & \\
\hline 9.PEI & $0.116^{* *}$ & $0.129^{* *}$ & $0.169^{* * *}$ & 0.040 & $0.170^{* * *}$ & $-0.085^{*}$ & $-0.196^{* * *}$ & $0.549^{* * *}$ & 1 & & & & & & \\
\hline 10.PF & 0.007 & -0.046 & 0.050 & $-0.083^{*}$ & 0.061 & 0.048 & $0.542^{* * *}$ & -0.009 & $0.181^{* * *}$ & 1 & & & & & \\
\hline 11.PRD & $0.130^{* *}$ & $0.161^{* * *}$ & $0.120^{* *}$ & $0.126^{* * *}$ & $0.145^{* * *}$ & $-0.109^{* *}$ & $-0.480^{* * *}$ & $0.692^{* * *}$ & $0.558^{* * *}$ & $-0.094^{*}$ & 1 & & & & \\
\hline 12.POP & $0.139^{* * *}$ & $0.115^{* *}$ & $0.174^{* * *}$ & 0.075 & $0.133^{* * *}$ & 0.064 & $0.345^{* * *}$ & $0.291^{* * *}$ & $0.482^{* * *}$ & $0.428^{* * *}$ & $0.126^{* * *}$ & 1 & & & \\
\hline $13 . \mathrm{T}$ & -0.027 & $-0.082^{*}$ & $-0.084^{*}$ & $0.078^{*}$ & $-0.123^{* * *}$ & $0.175^{* * *}$ & $0.724^{* * *}$ & $-0.339^{* * *}$ & $-0.263^{* * *}$ & $0.298^{* * *}$ & $-0.393^{* * *}$ & $0.217^{* * *}$ & 1 & & \\
\hline 14.C & 0.027 & -0.010 & -0.038 & $0.137^{* * *}$ & -0.050 & $0.109^{* *}$ & $0.580^{* * *}$ & $-0.109^{* *}$ & -0.037 & $0.284^{* * *}$ & $-0.163^{* * *}$ & $0.232^{* * *}$ & $0.752^{* * *}$ & 1 & \\
\hline 15. A & $0.201^{* * *}$ & $0.240^{* * *}$ & $0.238^{* * *}$ & $0.111^{* *}$ & $0.228^{* * *}$ & $-0.102^{* *}$ & $-0.453^{* * *}$ & $0.502^{* * *}$ & $0.415^{* * *}$ & -0.067 & $0.582^{* * *}$ & 0.048 & $-0.263^{* * *}$ & 0.015 & 1 \\
\hline
\end{tabular}

Notes. ${ }^{*} p<0.05,{ }^{* *} p<0.01,{ }^{* * *} p<0.001$. sSP $=$ Shyness for self-presentation, $\mathrm{sSt}=$ Shyness towards stranger, $\mathrm{sNE}=\mathrm{Shyness}$ when facing negative evaluation, $\mathrm{sOS}=$ Shyness towards opposite sex, Uns $=$ Unassuming shyness, $\mathrm{PEW}=$ Paternal emotional warmth, $\mathrm{PSP}=$ Paternal severe punishment, $\mathrm{PEI}=\mathrm{Paternal}$ excessive interference, $\mathrm{PF}=$

Paternal favoring, $\mathrm{PRD}=$ Paternal rejection and deny, $\mathrm{POP}=$ Paternal overprotection, $\mathrm{T}=$ Trust, $\mathrm{C}=$ Communication, $\mathrm{A}=\mathrm{Alienation}$. 
Table 2

Correlation Matrix for Maternal Style, Mather-Child Attachment and Shyness

\begin{tabular}{|c|c|c|c|c|c|c|c|c|c|c|c|c|c|c|}
\hline & 1 & 2 & 3 & 4 & 5 & 6 & 7 & 8 & 9 & 10 & 11 & 12 & 13 & 14 \\
\hline 1.Shy-ness & 1 & & & & & & & & & & & & & \\
\hline 2.sSP & $0.886^{* * *}$ & 1 & & & & & & & & & & & & \\
\hline 3.sSt & $0.877^{* * *}$ & $0.750^{* * *}$ & 1 & & & & & & & & & & & \\
\hline 4.sNE & $0.766^{* * *}$ & $0.571^{* * *}$ & $0.521^{* * *}$ & 1 & & & & & & & & & & \\
\hline $5 . \mathrm{sOS}$ & $0.848^{* * *}$ & $0.717^{* * *}$ & $0.784^{* * *}$ & $0.489^{* * *}$ & 1 & & & & & & & & & \\
\hline 6.Uns & $0.600^{* * *}$ & $0.444^{* * *}$ & $0.392^{* * *}$ & $0.491^{* * *}$ & $0.259^{* * *}$ & 1 & & & & & & & & \\
\hline 7.MEW & -0.074 & $-0.181^{* * *}$ & $-0.123^{* * *}$ & 0.056 & $-0.157^{* * *}$ & $0.188^{* * *}$ & 1 & & & & & & & \\
\hline 8.MEIO & $0.197^{* * *}$ & $0.162^{* * *}$ & $0.233^{* * *}$ & $0.188^{* * *}$ & $0.178^{* * *}$ & 0.007 & 0.056 & 1 & & & & & & \\
\hline 9.MRD & $0.169^{* * *}$ & $0.208^{* * *}$ & $0.223^{* * *}$ & $0.090^{*}$ & $0.202^{* * *}$ & $-0.132^{* * *}$ & $0.438^{* * *}$ & $0.552^{* * *}$ & 1 & & & & & \\
\hline 10.MSP & 0.044 & $0.133^{* * *}$ & $0.084^{*}$ & -0.029 & $0.109^{* *}$ & $-0.221^{* * *}$ & $-0.369^{* * *}$ & $0.419^{* * *}$ & $0.679^{* * *}$ & 1 & & & & \\
\hline 11.MF & -0.008 & -0.056 & 0.038 & $-0.111^{* *}$ & 0.07 & 0.02 & $0.507^{* * *}$ & $0.289^{* * *}$ & -0.034 & 0.012 & 1 & & & \\
\hline $12 . \mathrm{T}$ & -0.039 & $-0.089^{*}$ & $-0.104^{* *}$ & 0.075 & $-0.159^{* * *}$ & $0.202^{* * *}$ & $0.722^{* * *}$ & $-0.112^{* *}$ & $-0.490^{* * *}$ & $-0.345^{* * *}$ & $0.277^{* * *}$ & 1 & & \\
\hline 13.C & 0.052 & -0.002 & -0.015 & $0.165^{* * *}$ & -0.061 & $0.193^{* * *}$ & $0.592^{* * *}$ & 0.055 & $-0.287^{* * *}$ & $-0.125^{* *}$ & $0.266^{* * *}$ & $0.791^{* * *}$ & 1 & \\
\hline 14.A & $0.233^{* * *}$ & $0.279^{* * *}$ & $0.255^{* * *}$ & $0.130^{* * *}$ & $0.256^{* * *}$ & $-0.076^{*}$ & $-0.498^{* * *}$ & $0.284^{* * *}$ & $0.628^{* * *}$ & $0.534^{* * *}$ & $-0.127^{* * *}$ & $-0.301^{* * *}$ & -0.067 & 1 \\
\hline
\end{tabular}

Notes. $p<0.05, " p<0.01, " p<0.001$. MEW = Maternal emotional warmth, MEIO = Maternal excessive interference and overprotection, MRD = Maternal rejection and deny, MSP = Maternal severe punishment, MF = Maternal favoring. 


\section{The Parent-Child Attachment' Partial Mediating Effect on the Relationship Between Parenting Style and Shyness of High School Students}

According to the correlation analysis, paternal alienation was positively and significantly related with shyness, and was positively and significantly related with parental excessive interference, rejection and deny. The result implies that parental alienation may play a mediating role between parenting style and students' shyness. In this study, regression analysis was used to test the parental alienation's mediation between the parenting style and shyness (Wen, Zhang, Hou, \& Liu, 2004).

First of all, we test alienation's mediation between paternal rearing style and shyness. In the first step of regression analysis, we take high school students' shyness as dependent variable, and paternal emotional warmth, paternal excessive interference, rejection and deny dimensions as independent variables to test coefficient $\mathrm{c}_{1}$; at the second step, take the father-child alienation as dependent variable, and the paternal emotional warmth, paternal excessive interference, rejection and deny dimensions as independent variables to test coefficient $\mathrm{c}_{2}$; at the third step, take shyness as dependent variable, and the paternal emotional warmth, paternal excessive interference, rejection and deny dimensions and father-child alienation as dependent variables to test coefficient $\mathrm{b}_{1}$ and $\mathrm{c}_{1}$ '. Table 3 shows that the $\beta$ of paternal emotional warmth, paternal excessive interference, rejection and deny were significant, paternal emotional warmth $\left(c_{1}=0.130, p<0.01\right)$, paternal excessive interference $\left(c_{1}=\right.$ $0.116, p<0.01)$, and rejection and deny dimensions $\left(c_{1}=0.130, p<0.01\right)$ have a better prediction effect on shyness. At the third step of regression analysis, we can see that after father-child alienation was involved, coefficient $a_{1}$ and $b_{1}$ were significant, but $c_{1}$ was not significant, indicating that father-child alienation play a complete mediation effect between paternal rearing and high school students' shyness.

Table 3

The Tests on the Mediating Effects of Parent-Child Attachment on the Relationship Between Parenting Style and Students' Shyness

\begin{tabular}{|c|c|c|c|c|c|c|c|}
\hline \multicolumn{4}{|l|}{ Father } & \multicolumn{4}{|l|}{ Mother } \\
\hline \multicolumn{4}{|c|}{ Emotional warmth $_{X 1}$} & \multicolumn{4}{|c|}{ Excessive interference and protection $_{X 1}$} \\
\hline 1st step & $\mathrm{Y}=-0.097_{\mathrm{X} 1}$ & $S E=0.796$ & $t=-2.450^{*}$ & 1st step & $\mathrm{Y}=0.197_{\mathrm{X} 1}$ & $S E=0.791$ & $t=5.108^{* * *}$ \\
\hline 2nd step & $\mathrm{M}=-0.453_{\mathrm{X} 1}$ & $S E=0.185$ & $t=-12.968^{* * *}$ & 2nd step & $\mathrm{M}=0.284_{\mathrm{X} 1}$ & $S E=0.037$ & $t=7.589^{* * *}$ \\
\hline \multirow[t]{2}{*}{ 3rd step } & $\mathrm{Y}=0.003_{\mathrm{X} 1}$ & $S E=0.874$ & $t=0.077$ & 3rd step & $\mathrm{Y}=0.144_{\mathrm{X} 1}$ & $S E=0.807$ & $t=3.636^{* * *}$ \\
\hline & $+0.214 \mathrm{~m}$ & $S E=0.876$ & $t=4.933^{* * *}$ & & $+0.191 \mathrm{~m}$ & $S E=0.801$ & $t=4.823^{* * *}$ \\
\hline \multicolumn{4}{|c|}{ Excessive interference $_{X 2}$} & \multicolumn{4}{|c|}{ Rejection and deny x2 } \\
\hline 1 st step & $\mathrm{Y}=0.116_{\mathrm{X} 2}$ & $S E=0.795$ & $t=2.993^{* *}$ & 1 st step & $\mathrm{Y}=0.169_{\mathrm{X} 2}$ & $S E=0.785$ & $t=4.396^{* * *}$ \\
\hline 2nd step & $\mathrm{M}=0.415_{\mathrm{X} 2}$ & $S E=0.036$ & $t=11.775^{* * *}$ & 2nd step & $\mathrm{M}=0.628_{\mathrm{X} 2}$ & $S E=0.030$ & $t=20.895^{* * *}$ \\
\hline \multirow[t]{2}{*}{ 3rd step } & $\mathrm{Y}=0.032_{\mathrm{X} 2}$ & $S E=0.867$ & $t=0.753$ & 3rd step & $\mathrm{Y}=0.037_{\mathrm{X} 2}$ & $S E=0.995$ & $t=0.755$ \\
\hline & $+0.185 \mathrm{~m}$ & $S E=0.854$ & $t=4.348^{* * *}$ & & $+0.211 \mathrm{~m}$ & $S E=0.992$ & $t=4.312^{* * *}$ \\
\hline \multicolumn{8}{|c|}{ Rejection and deny $X 3$} \\
\hline 1 st step & $\mathrm{Y}=0.130_{\mathrm{X} 3}$ & $S E=0.788$ & $t=3.361^{* * *}$ & & & & \\
\hline 2nd step & $\mathrm{M}=0.582_{\mathrm{X} 3}$ & $S E=0.031$ & $t=18.583^{* * *}$ & & & & \\
\hline \multirow[t]{2}{*}{ 3rd step } & $\mathrm{Y}=0.005_{\mathrm{X} 3}$ & $S E=0.960$ & $t=0.102$ & & & & \\
\hline & $+0.203 \mathrm{~m}$ & $S E=0.954$ & $t=4.294^{* * *}$ & & & & \\
\hline
\end{tabular}

Secondly, we use the same method to examine the mother-child alienation between the maternal rearing style and shyness. In the first step of regression analysis, we take the high school students' shyness as dependent variable, and maternal excessive interference and protection, rejection and deny dimensions as 
independent variables to test coefficient $\mathrm{c}_{1}$; at the second step, take the mother-child alienation as dependent variable, and maternal excessive interference and protection, rejection and deny dimensions as independent variables to test coefficient $c_{2}$; at the third step, take the shyness as dependent variable, and maternal excessive interference and protection, rejection and deny dimensions and mother-child alienation as independent variables to test coefficient $b_{1}$ and $c_{1}$. Table 3 shows that the $\beta$ value of maternal excessive interference and protection, rejection and deny dimensions were significant, maternal rearing style (excessive interference and protection, rejection and deny) also has a prediction effect on shyness. In the third step of regression analysis, we can see that after mother-child alienation was involved, coefficient $a_{1}, b_{1}$ and $c_{1}$ of maternal excessive interference and protection were all significant, so after Sobel test we found that mother-child alienation play a partial mediation effect between maternal excessive interference and protection and students' shyness, and the proportion of the mediation effect is $0.284 \times 0.191 / 0.197=27.54 \%$. However, coefficient $a_{1}, b_{1}$ of maternal rejection and deny were significant, $\mathrm{c}_{1}$ was not significant, indicating that mother-child alienation play a complete mediation effect between maternal rejection and deny and students' shyness.

\section{Discussion}

The current study examined the relationship between parenting style, parent-child attachment and shyness of high school students. Results indicated that there is a close relationship between parenting style, parent-child attachment, and students' shyness.

Firstly, parenting style is related closely with shyness of high school students. We find that the parental rejection and deny, excessive interference and over-protection were positively related with high school students' shyness, and have a significant and positive prediction on shyness, however, paternal warmth has significant negative relationship with shyness, and has a significant negative prediction on high school students' shyness. The result is consistent with other scholars (Chen et al., 2014). For example, Schlette took 132 senior high school students as the research subjects, and found that rejecting rearing behavior and lack of emotional warmth in childhood, seemed to constitute a risk factor for development of high harm avoidant behavior (anticipatory worry, fear of uncertainty, shyness) and low self-directed behavior (blaming others, helplessness, lack of self-acceptance and low self-esteem) (Schlette et al., 1998). The reason for this is because parents' excessive interference and protection will limit their children's independent ability of acting, affect their normal communication with others. When they have to face some situations and problems alone, more withdrawal behaviors may turn up which can lead to a vicious cycle of shyness. The parental deny would make their children experience more frustrations and impair their self-esteem, as a consequence they fear of expressing themselves and improve the level of self-restriction, finally lead to the emergence of shyness (An \& Sheng, 2013). On the contrary, the parenting style of emotional warmth and trust can give children more care and sense of security, which can increase children's psychological freedom, self-confidence and communicational enthusiasm with their parents, thereby it may reduce the possibility of shyness. Moreover, the previous studies were much more about maternal rearing style and mother-child attachment (Cortney, Larry, \& Christin, 2012), and relatively less about paternal rearing style and father-child attachment. But these studies mostly were for the young children. In current study, we found that paternal emotional warmth has significant and negative prediction on high school students' shyness, which suggests, the role of father began to highlight with the growth of high school students, a father one often gives children emotional warmth can reduce their children's shyness. 
Secondly, parent-child attachment also has a close relationship with high school students' shyness. We found that parental alienation was positively and significantly related with shyness, and had a significant and positive predictive effect on shyness. Above results were consistent with previous studies, unsecure attachment can significantly predict the shyness (Chen, 2012). This shows that the parent-child relationship has an important influence on the children's shyness. If parents always alienate their children, the children can't feel parents' love, then it is possible for them to generate anxiety and insecurity, as a result, they may tend to be emotional autism in order to protect themselves from hurting. Therefore, they are easy to be self-contemptuous, and can't handle with the stressful situations, finally resulting in shyness (Thomas \& Kristy, 2012). On the contrary, when parents trust their children, and communicate much more with children, accordingly a better parent-child relationship would be established, so children would gain more confidence and sense of security, their psychological inferiority and timid behaviors would also be reduced and behave freely when facing others (Prevatt, 2003; Susanna et al., 2014).

Finally, we found that parent-child attachment plays a mediating role on the relationship between parenting style and shyness. Paternal alienation play a complete mediation between paternal rearing style (emotional warmth, excessive interference, rejection and deny) and shyness. Maternal alienation has a partial mediation between maternal excessive protection and interference and shyness, also has a complete mediation between maternal reject and deny and shyness. The results shows that, on one hand, high school students' shyness can be directly affected by parenting style, but more through influencing the quality of parent-child relationship. Specifically, if parents educate their children with warmth and understanding attitudes, it would be easy to set up a better parent-child relationship of trust and communication, which can give children more confidence and security, reduce children's shyness; conversely, if parents treat their children with excessive interference or over-protection, or reject and deny attitudes, it may form a parent-child relationship of alienation, which render children feel neglect, isolate and helpless, consequently leading to children's shyness.

In summary, during the late adolescence stage, the influence of parenting style on children's shyness still exists. This influence is directly reflected in the effect of parenting style on shyness. Meanwhile, it is also reflected through the influence of the parent-child attachment. Once the alienation relationship was formed between parents and children, it will greatly increase high school students' shyness. This result reminds parents that parenting style and attachment patterns play an important role in the formation of children's shyness. Parents should adopt positive parenting style, such as emotional warmth, and try to avoid the negative parenting style, such as excessive interference, rejection and deny. Thereby a good parent-child relationship can be formed, which contribute to reducing late adolescence students' shyness.

\section{Reference}

An, X., \& Sheng, Y. (2013). Relationship between parenting, shyness and fear of negative evaluation. China Journal of Health Psychology, 21(3), 434-437.

Brown, G. L., Mangelsdorf, S. C., \& Neff, C. (2012). Father involvement, paternal sensitivity, and father-child attachment security in the first 3 years. Journal of Family Psychology, 26, 421-430.

Chen, Y. (2013). The structure and characteristics as well as the effect of heredity and environment on shyness among junior middle school students (Doctoral dissertation, Shandong Normal University, 2013).

Chen, X., Liu, M., \& Li, D. (2000). Parental warmth, control, and indulgence and their relations to adjustment in Chinese children: A longitudinal study. Journal of Family Psychology, 14(3), 401-409.

Chen, B. (2012). The association between self-reported mother-child attachment and social initiative and withdrawal in Chinese school-aged children. The Journal of Genetic Psychology, 173(3), 279-301. 
Chen et al. (2015). Compiling the shyness scale for Chinese junior high school students. Journal of Shandong Normal University (Natural Science), 30(1), 75-78.

Chen, X., Zhang, G., \& Liang, Z. et al. (2014). Relations of behavioral inhibition with shyness and social competence in Chinese children: Moderating effects of maternal parenting. Infant and Child Development, 23, 343-352.

Cortney, A. E., Larry, J. N., \& Christin, L. P. (2012). Understanding relations among children's shy and antisocial/aggressive behaviors and mothers' parenting: The role of maternal beliefs. Journal of Developmental Psychology, 58(3), 341-374.

Frances, F. P. (2003). The contributions of parenting practices in risk and resiliency model of children's adjustment. The British journal of development psychology, 21(4), 469-470.

Henderson, L., \& Zimbardo, P. (1998). Shyness: Encyclopedia of mental health. San Diego: Academic Press.

Han, L., Gao, F., Ping, F., \& Pan, Q. (2012). The mechanism of parenting style effect on shyness. Studies of Psychology and Behavior, 10(6), 464-467.

Jakobsen, I. S., Horwood, L. J., \& Fergusson, D. M. (2012). Childhood anxiety/withdrawal, adolescent parent-child attachment and later risk of depression and anxiety disorder. Journal of Child and Family Studies, 21(2), 303-310.

Liu, Q., Zhou, S., Yang, H., Chu, Y., \& Liu, L. (2009). Adolescent's adult attachment and its relationship with parenting styles. Chinese Journal of Clinical Psychology, 17(5), 615-616.

Prevatt, F. F. (2003). The contribution of parenting practices in a risk and resiliency model of children's adjustment. British Journal of Developmental Psychology, 21(4), 469-480.

Paul, S., Sven, B., \& Martin, E. et al. (1998). Perceived parental rearing behaviors and temperament and character in healthy adults. Personal Individual Differences, 24(5), 661-668.

Susanna, P., Roberto, B., Barry, H. S., Sheri, M., \& Leslie, A. (2014). Early child-parent attachment and peer relations: A meta-analysis of recent research. Journal of Family Psychology, 28(1), 118-123.

Stephen, S., Jacqueline, B., Matthew, W., Sajid, H., \& Thomas, G. (2011). Attachment in adolescence: Overlap with parenting and unique prediction of behavioral adjustment. Journal of Child Psychology and Psychiatry, 52(10), 1052-1062.

Thomas, H. O., \& Kristy, E. B. (2012). A parent-child interactional model of social anxiety disorder in youth. Clinical Child and Family Psychology Review, 15(1), 81-91.

Wu, Q., \& Wang, M. (2014). Relationship among parent-child attachment, peer attachment and anxiety in adolescents. Chinese Journal of Clinical Psychology, 22(4), 684-687.

Wen, Z., Zhang, L., Hou, J., \& Liu, H. (2004). Testing and application of the mediating effects. Acta Psychologica Sinica, 36(5), 614-620.

Xu, X. (2014). The relationship between shyness and parental rearing styles. China Journal of Health Psychology, 22(6), 941-942.

Yue et al. (1993). Preliminary revision of EMBU and its application in neurotic patients. Chinese Mental Health Journal, 7(3), 97-101. 